\title{
SOCS2 negatively regulates growth hormone action in vitro and in vivo
}

\author{
Christopher J. Greenhalgh, ${ }^{1}$ Elizabeth Rico-Bautista, ${ }^{2}$ Mattias Lorentzon, ${ }^{3}$ Anne L. Thaus, ${ }^{4}$ \\ Phillip O. Morgan, ${ }^{1}$ Tracy A. Willson, ${ }^{1}$ Panagiota Zervoudakis, ${ }^{4}$ Donald Metcalf, ${ }^{1}$ lan Street, ${ }^{1}$ \\ Nicos A. Nicola, ${ }^{1}$ Andrew D. Nash, ${ }^{4}$ Louis J. Fabri, ${ }^{4}$ Gunnar Norstedt, ${ }^{2}$ Claes Ohlsson, ${ }^{3}$ \\ Amilcar Flores-Morales, ${ }^{2}$ Warren S. Alexander, ${ }^{1}$ and Douglas J. Hilton ${ }^{1}$
}

\begin{abstract}
${ }^{1}$ Cancer and Haematology Division, The Walter and Eliza Hall Institute of Medical Research (WEHI) and the Cooperative Centre for Cellular Growth Factors, Parkville, Victoria, Australia. ${ }^{2}$ Department of Molecular Medicine, Karolinska Institute, Karolinska Hospital, Stockholm, Sweden. ${ }^{3}$ Center for Bone Research at the Sahlgrenska Academy, Department of Internal Medicine, Gothenburg University, Gothenburg, Sweden. ${ }^{4}$ Amrad Corporation Ltd., Burnley, Victoria, Australia.
\end{abstract}

\begin{abstract}
Mice deficient in SOCS2 display an excessive growth phenotype characterized by a 30-50\% increase in mature body size. Here we show that the SOCS2 ${ }^{-/-}$phenotype is dependent upon the presence of endogenous growth hormone $(\mathrm{GH})$ and that treatment with exogenous $\mathrm{GH}$ induced excessive growth in mice lacking both endogenous GH and SOCS2. This was reflected in terms of overall body weight, body and bone lengths, and the weight of internal organs and tissues. A heightened response to GH was also measured by examining GH-responsive genes expressed in the liver after exogenous $\mathrm{GH}$ administration. To further understand the link between SOCS2 and the GH-signaling cascade, we investigated the nature of these interactions using structure/function and biochemical interaction studies. Analysis of the 3 structural motifs of the SOCS2 molecule revealed that each plays a crucial role in SOCS2 function, with the conserved SOCS-box motif being essential for all inhibitory function. SOCS2 was found to bind 2 phosphorylated tyrosines on the GH receptor, and mutational analysis of these amino acids showed that both were essential for SOCS2 function. Together, the data provide clear evidence that SOCS2 is a negative regulator of GH signaling.
\end{abstract}

\section{Introduction}

Growth hormone $(\mathrm{GH})$ is the major growth factor of the somatotrophic axis involved in the promotion of postnatal longitudinal growth. It acts via direct and indirect mechanisms, including the use of second messengers such as IGF-1. GH also has other potent effects, including modulation of lipid, glucose, nitrogen, and mineral metabolism, promotion of lipolysis, increase of amino acid uptake and protein synthesis, and decrease of protein breakdown (1). In contrast, chronic elevations of the hormone, as seen in acromegalic patients, causes gigantism, hyperinsulinemia, impaired glucose tolerance, insulin resistance, and finally diabetes (2).

The number of clinical applications of GH are increasing, but one of the most important has been the stimulation of growth in children. Clinical studies have demonstrated that daily exogenous GH injection is a successful treatment for growth disorders in children, but its effectiveness is limited by the nature of the growth defect and the age of diagnosis. However, this treatment can have considerable side effects on carbohydrate metabolism, with some studies indicating increased fasting blood glucose and diabetes in children undergoing GH therapy (3).

$\mathrm{GH}$ administration is also an effective means of treating GHdeficient adults that suffer from increased fat mass, decreased lean muscle and muscle strength, and reduced exercise capacity. Exogenous GH treatment improves the metabolic profile,

Nonstandard abbreviations used: FDR, false discovery rate; $\mathrm{GH}$, growth hormone; GHRHR, GH-releasing hormone receptor; LHRE, lactogenic hormone response element; rpGH, recombinant pig growth hormone; SHP2, Src homology 2-containing tyrosine phosphatase.

Conflict of interest: The authors have declared that no conflict of interest exists.

Citation for this article: J. Clin. Invest. 115:397-406 (2005)

doi:10.1172/JCI200522710. enhances the quality of life, increases lean muscle mass with a reduction in body fat, reduces total cholesterol, and increases lipolysis (4), but it can also lead to the deterioration of glucose metabolism (5). Overall, the use of exogenous GH for the treatment of GH deficiency is extremely useful but can have side effects or no additional benefits beyond particular dosages. Consequently, a method of amplifying the growth-promoting and anabolic effects of GH would be a very effective way to deal with this problem. One strategy would be to target or inactivate molecules that act to negatively regulate $\mathrm{GH}$ signaling.

The SOCS proteins are a family of negative regulatory proteins that are expressed in response to activation of a wide range of cytokine and growth factor signal cascades, particularly those that utilize JAK/STAT signaling systems. There are 8 known members (SOCS1-SOCS7 and cytokine-inducible SH2 domaincontaining protein), and a number of these molecules have been shown, in in vitro overexpression systems, to bind to and inhibit a wide array of cytokine/growth factor signaling molecules, including GH (reviewed in 6,7). Despite in vitro evidence that SOCS proteins display a high degree of promiscuity, clear physiological roles for a number of the SOCS members have been delineated through mouse genetic studies. SOCS1 has been shown to be involved in negatively regulating IFN $\gamma$ responses (8), mammary gland function/prolactin signaling (9) and $\gamma_{c}$-using cytokines (10), whereas SOCS3 plays central roles in placental development (11), as well as leukemia inhibitory factor (12), IL-6 (13-15), and granulocyte-CSF signaling (16).

Genetic studies have also shown that SOCS proteins play important roles in growth and development. SOCS2 knockout mice exhibit gigantism characterized by an increase in body weight and length, alterations in major urinary protein levels, thickening of dermal layers, and elevation of IGF-1 mRNA in 

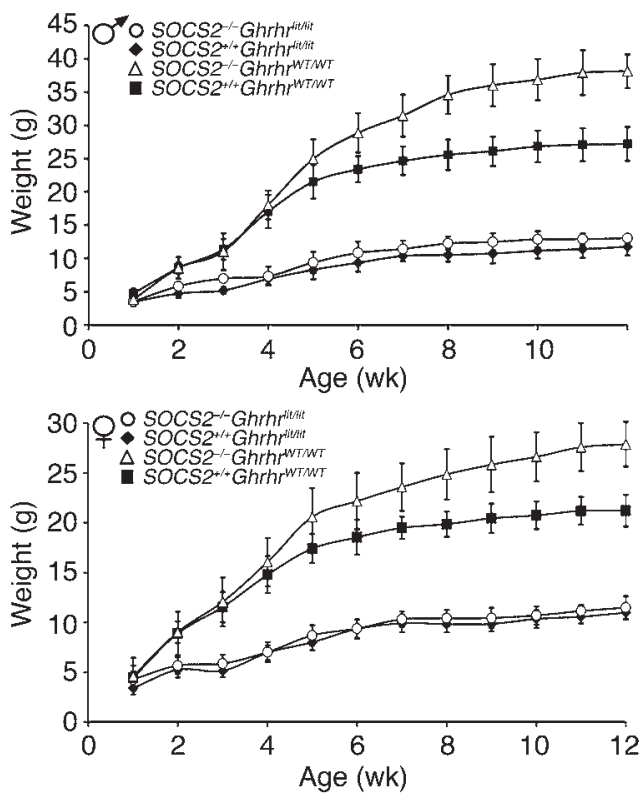

some tissues (17). These phenotypes are observed in other models of excessive growth such as GH transgenic (18), IGF-1 transgenic (19) and high-growth mice (20), suggesting that SOCS2 may regulate some components of the somatotrophic pathway. While a number of studies have indicated that SOCS2 plays a role in GH signaling in vitro $(21,22)$, SOCS2 has also been found to bind to the IGF-1 receptor in yeast 2 -hybrid studies $(23,24)$. We have also shown that STAT5b, one of the key mediators of GH action $(25,26)$, plays an important role in the development of

\section{Figure 1}

$\mathrm{GH}$ is essential for the SOCS2-/- phenotype. Growth curves for SOCS2 $2^{+/}$Ghrhrlit/lit, SOCS2-/-Ghrhrlit/lit, SOCS2+/+GhrhrWT/WT and SOCS2--GhrhrWT/WT mice of both sexes over a 12-week period. At least 10-15 male mice were used at each point for the male growth curves and 6-17 female mice are represented at each time point for the female curves.

the SOCS2 $2^{-/-}$phenotype, and that modest prolongation of STAT5 signaling is evident in primary hepatocyte cultures of SOCS2-deficient mice stimulated with GH (27). Furthermore, using transgenic mice that overexpress a Flag-tagged SOCS2 construct, we have shown that SOCS2 interacts with endogenous GH receptors from a range of mouse tissues (28). Although the findings to date indicate that SOCS2 plays some role in the regulation of GH signaling, whether SOCS2 directly regulates GH signaling or IGF signaling, or both, remains an open question. A clear in vivo demonstration that the SOCS2-deficient phenotype relies upon the presence of GH would be invaluable in deciphering whether SOCS2 is a major negative regulator of GH action and would justify SOCS2 as a target for new therapeutic strategies.

Here we demonstrate that the presence of SOCS2 is dependent upon an intact somatotrophic pathway and that many aspects of the SOCS2-/- phenotype can be recapitulated with GH administration to mice lacking SOCS2 and endogenous GH. We further characterized the interaction between SOCS2 and the GH receptor and found that SOCS2 binds to 2 phosphorylated tyrosines on the $\mathrm{GH}$ receptor that are also targeted by another signaling regulator, Src homology 2-containing tyrosine phosphatase (SHP2), and these tyrosine residues are essential for the regulatory effects of SOCS2. Together, our data indicate that SOCS2 is a key modulator of GH sensitivity in vivo.

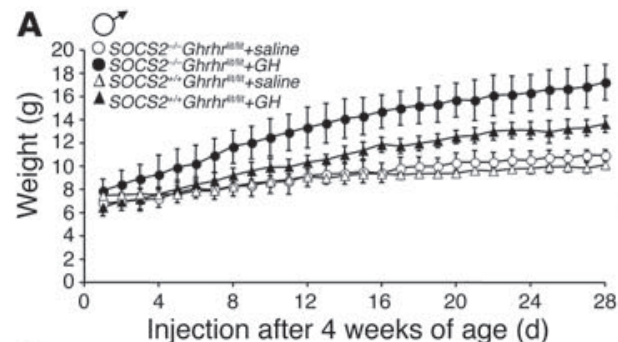

B

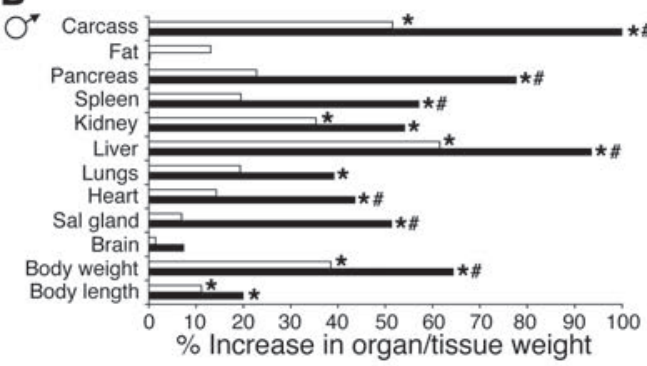

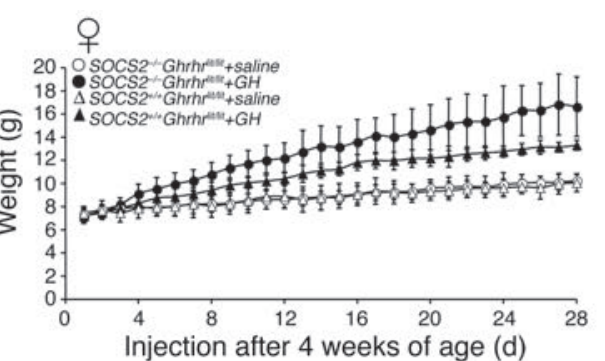
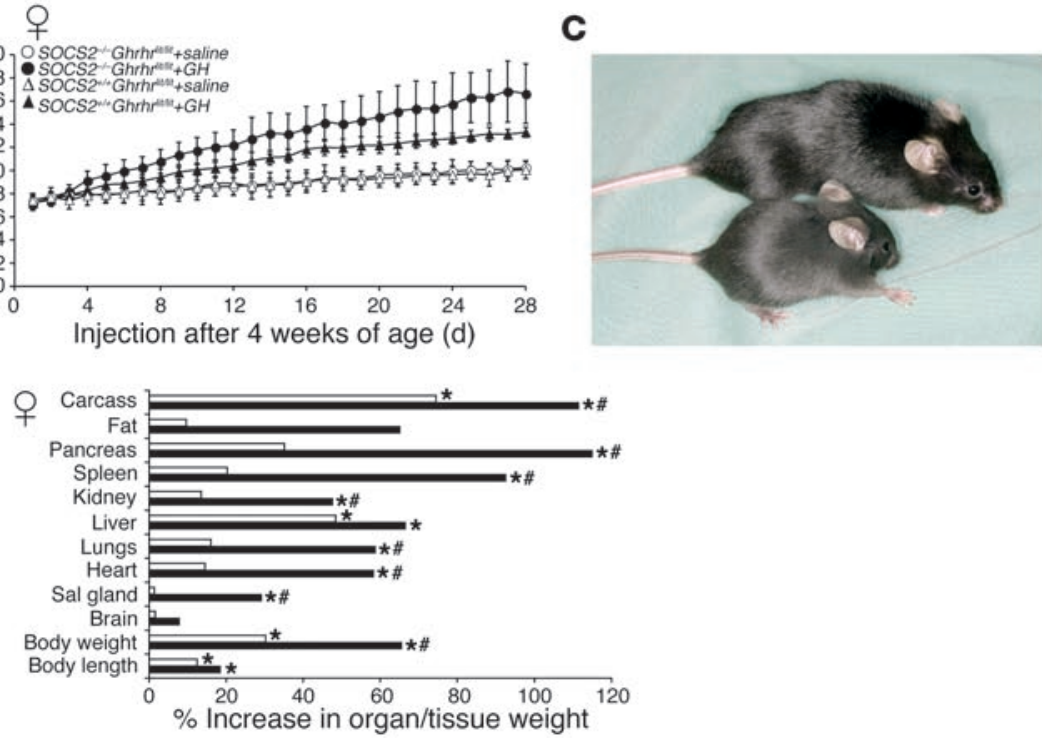

Figure 2

SOCS2 controls growth responses to GH. (A) Male and female SOCS2+/+Ghrhrlitlit and SOCS2-/-Ghrhrit/lit mice were weighed daily before being injected twice daily with $10 \mu \mathrm{g} \mathrm{rpGH}$ or saline for 28 days from 4 weeks of age. Growth curves were constructed from 5-10 male mice or 5-7 female mice per treatment group. (B) Differences in organ weights of male and female SOCS2 ${ }^{+/+}$Ghrhritlit (white bars) and SOCS2 ${ }^{-/-G h r h r i t / l i t}$ (black bars) mice are represented as a percentage increase over the mean of saline-injected mouse organ weights. ${ }^{*} P<0.05$ vs. saline-injected

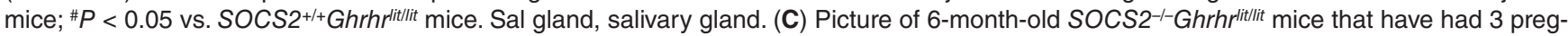
nancies (upper) or no pregnancies (lower). 
A
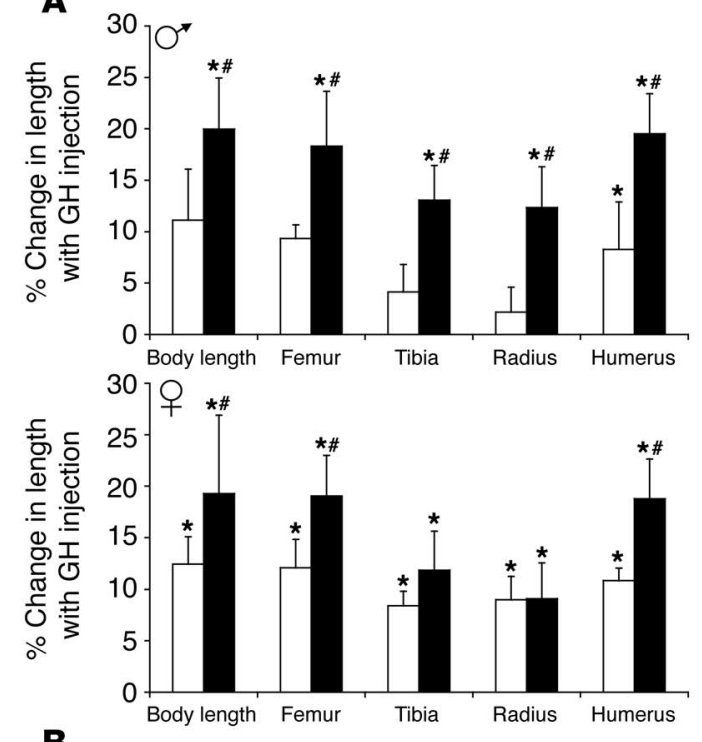

B

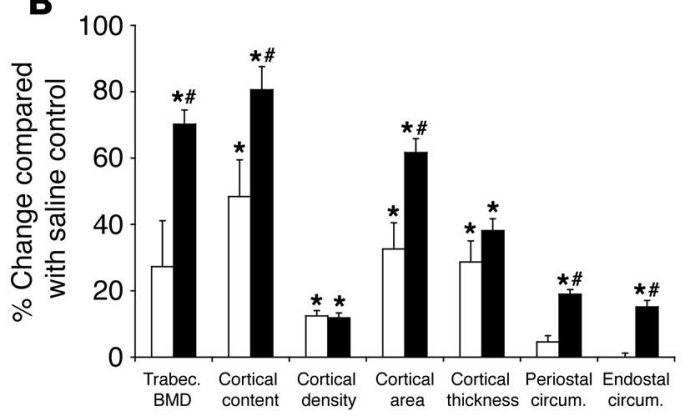

\section{Results}

Removal of GH deletes the SOCS2-/- phenotype. Previous work with SOCS2-deficient mice has suggested that SOCS2 acts to negatively regulate the actions of $\mathrm{GH}(17,27,28)$. To test this hypothesis, we crossed male and female SOCS2-/- mice with Ghrbrit/lit (little) mice, a mutant strain with a point mutation in the GH-releasing hormone receptor (GHRHR) that causes a nearly complete deficiency in pituitary-derived circulating $\mathrm{GH}$ and induces dwarfism (29). We used little mice because other models of GH deficiency or inaction do not exist (GH knockout mice), do not allow for $\mathrm{GH}$ growth recapitulation experiments ( $\mathrm{GH}$ receptor knockout mice), or have other complicating deficiencies that could confound results (Ames and Snell dwarf mice). Growth curves were measured for Ghrbrlit/lit and SOCS2 $2^{-/-}$Ghrbrlit/lit mice over a 12-week period (Figure 1). Female SOCS2 ${ }^{-/-}$Ghrbrlit/lit mouse growth curves were indistinguishable from those of female Ghrbrlit/lit mice, whereas male SOCS2-/-Ghrbrit/lit mice were only slightly larger than Ghrbrit/lit mice by 12 weeks of age, suggesting that GH signaling is required for development of the SOCS2 $2^{-1-}$ phenotype.

SOCS2 modulates growth responses to GH. To definitively classify SOCS2 as a negative regulator of GH action, it is important not only to demonstrate dependence of the excess growth in SOCS2-/mice on the presence of $\mathrm{GH}$, but also to recapitulate the phenotype by supplying the cytokine exogenously to GH-deficient SOCS2 ${ }^{-/}$mice. Four-week-old male and female SOCS2 ${ }^{+/+} \mathrm{Gbrhr}^{\text {lit/lit }}$ and SOCS2-/-Ghrbrit/lit mice were injected subcutaneously twice daily with $10 \mu \mathrm{g} \mathrm{GH}$ or saline for 4 weeks, and body weights were

\section{Figure 3}

SOCS2 controls bone growth parameters. (A) Long bone lengths and femur morphometric data (B) were measured from 4-9 male mice of both genotypes. Data for each parameter is expressed as the percentage change with $\mathrm{GH}$ treatment compared to saline controls for SOCS2 $2^{+/} G$ Grhrlit/lit (white bars) and SOCS2 ${ }^{-/-}$Ghrhrlitlit (black bars) mice. ${ }^{*} P<0.05$, vs. saline-treated mice; ${ }^{\#} P<0.05$ vs. SOCS2+/+ Ghrhrit/lit mice. Trabec. BMD, trabecular bone mineral density; circum., circumference.

measured daily (Figure 2A). Growth was considerably exaggerated in male SOCS2-/-Ghrbrit/lit mice receiving GH over that in male SOCS2 ${ }^{+/+} \mathrm{Ghrbr}^{\text {lit } / \text { lit }}$ mice receiving GH when evaluated against each genotype given saline injections (by 58\% and 35\%, respectively). This trend was also observed in SOCS2 $2^{-/-}$Ghrhr ${ }^{\text {lit } / l i t}$ and SOCS2 $2^{+/+}$ Ghrbrlit/lit females given GH injections when evaluated against saline-treated mice (by $68 \%$ and $35 \%$, respectively).

Analysis of organ and tissue weights from these mice further emphasized the role that SOCS2 plays in attenuating GH-driven growth (Figure 2B). The magnitude of GH-stimulated organ weight gain in male SOCS2 ${ }^{--}$Ghrbrlit/lit mice was significantly greater than that observed in $\mathrm{SOCS}^{+/+} \mathrm{Ghrbr} r^{\text {lit } / \text { lit }}$ mice in most tissues, particularly the carcass, which doubled in weight. The only tissue that decreased in weight was abdominal fat. Similar trends for organ weights were also observed in female SOCS2 $2^{-/}$Ghrbrlit/lit mice.

Another feature of the SOCS2 $2^{--}$gigantic phenotype was the deposition of large amounts of collagen in ducts and vessels throughout the body, particularly in the skin (17). The enhanced growth response of SOCS2 ${ }^{--}$Ghrbrlit/lit mice to GH was also reflected in modest increases in skin thickness of most male SOCS2 ${ }^{-/-}$Ghrbr $r^{\text {lit lit }}$ mice at the end of GH-induced growth experiments (data not shown).

An interesting aspect of the female Ghrbrlit/lit mouse phenotype is the growth recovery observed throughout pregnancy that returns Ghrhrlit/lit females to wild-type size after 3 pregnancies (30). Although unmated SOCS2 ${ }^{+/+} \mathrm{Ghrbr}^{\text {lit/lit }}$ and SOCS2 ${ }^{-/-}$Ghrbr ${ }^{\text {lit } / \text { lit }}$ female mice were the same size, remarkably, following several pregnancies, SOCS2 $2^{-/}$Ghrbrlit/lit female mice not only reached wild-type female weight but attained the dimensions of adult SOCS2 ${ }^{-1-}$ female mice (Figure $2 \mathrm{C}$ and data not shown), indicating a hyperresponsiveness to a pregnancy-induced growth factor, such as prolactin or placental lactogens.

Increases in body weight were also accompanied by enlarged skeletal dimensions. Male SOCS2-/-Ghrbrlit/lit mice displayed enhanced body length compared to $S O C S 2^{+/+} G h r b r$ lit/lit mice upon $\mathrm{GH}$ treatment, and measurements of long bones revealed sig-

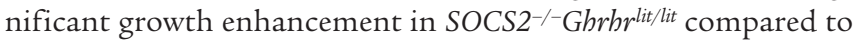
$\mathrm{SOCS}^{+/+} \mathrm{Ghrbr}^{l i t / l i t}$ mice (Figure $3 \mathrm{~A}$ ). Computer tomography scanning of femurs from these mice revealed significant enhancement of a number of bone growth and strength parameters in male mice lacking SOCS2 (Figure 3B), but many of these changes were not observed in female mice (data not shown).

$\mathrm{GH}$-induced gene expression in livers of mice lacking SOCS2. While the studies described above provide good physiological evidence that SOCS2 attenuates GH signaling, we wished to examine whether a hyperresponsiveness to GH could be detected in the liver gene expression profiles of SOCS2 ${ }^{-/-}$Ghrhr lit/lit $^{\text {mice compared }}$ to SOCS2 ${ }^{+/+} \mathrm{Ghrhr} r^{\text {lit/lit }}$ mice, identify GH-responsive genes that are regulated by SOCS2, and gain insight into the molecular mechanism of SOCS2 action from the expression profile differences. We performed microarray analysis on liver RNA extracts from male 

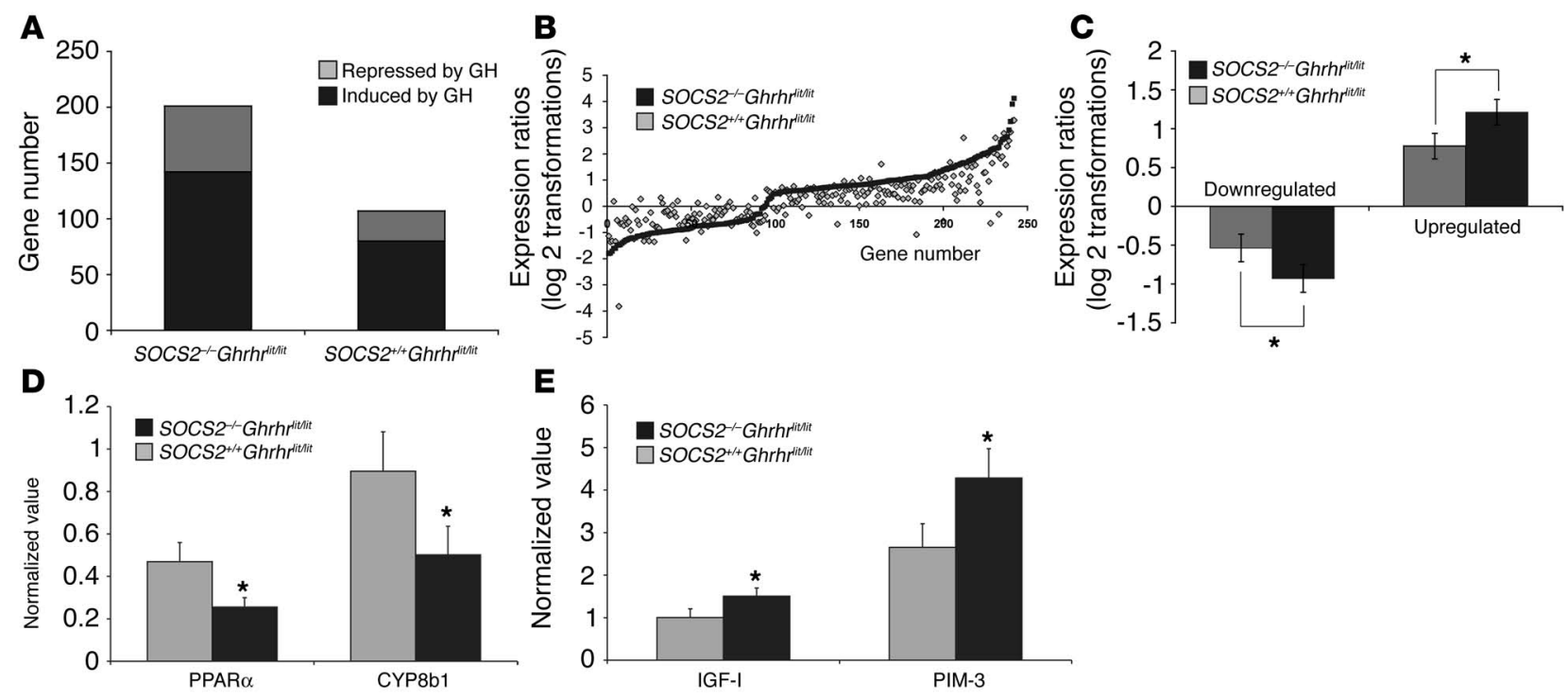

Figure 4

SOCS2 regulates $\mathrm{GH}$-induced gene expression in the liver. (A) The number of GH-regulated genes in the liver of SOCS2 ${ }^{+/+} \mathrm{Ghrhrlit/it}$ and SOCS2 ${ }^{--}$Ghrhrit/lit mice 2 hours after GH injection was compared based on SAM analysis (5\% FDR) for 4 independently replicated treatments. Individual genes are arranged along the $x$ axis according to the value order of decreases and increases in gene expression of SOCS2 $2^{--}$Ghrhrit/lit mice. The $y$ axis shows the log ratio of the transcript signals in GH-treated SOCS2 ${ }^{+/+G h r h r l i t / l i t}$ and SOCS2 ${ }^{-/-G h r h r l i t / l i t}$ mice (B), and the average changes in gene expression in SOCS2+/+Ghrhrlitlit and SOCS2-/-Ghrhrlitlit was also examined (C). Real-time RT-PCR results from SOCS2 ${ }^{+/+}$Ghrhrit/lit and SOCS2 ${ }^{-/-}$Ghrhrlitlit mouse livers showing genes that were downregulated (D) or upregulated (E). ${ }^{*} P<0.05$.

SOCS2-/-Ghrbrit/lit and SOCS2 ${ }^{+/+}$Ghrbrlit/lit mice injected with GH 2 hours prior to sacrifice. We had previously shown that SOCS2 mRNA levels reach maximal concentrations 2 hours after $\mathrm{GH}$ treatment in the BRL4 hepatocyte cell line (31); therefore we supposed that differences in liver mRNA between SOCS2-/-Ghrbrlit/lit

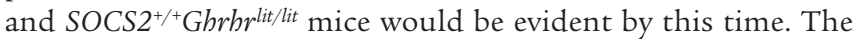
number of genes induced and repressed by $\mathrm{GH}$ injection was increased almost 2-fold in the SOCS2 ${ }^{-/-}$Ghrbrlit lit livers compared to $S O C S 2^{+/+} \mathrm{Ghrbr}^{\text {lit } / \text { lit }}$ livers (Figure $4 \mathrm{~A}$ ). Comparative analysis of genes with altered expression levels from both genotypes revealed considerable differences in the degree of change, with SOCS2 ${ }^{-/-}$Ghrbrlit/lit mice demonstrating a hyperresponsiveness in nearly all cases (Figure 4B). Examination of the average change in gene expression of the SOCS2 ${ }^{+/+} \mathrm{Ghrhr}^{\text {lit/lit }}$ and SOCS2 $2^{-/-} \mathrm{Ghrbr}^{\text {lit/lit }}$ regulated gene populations also emphasizes the significant over-response of mice that lack SOCS2 (Figure 4C and Supplemental Table 1; supplemental material available online with this article; doi:10.1172/ JCI200522710DS1). Hyperresponsiveness to GH is evident for well-known GH-regulated genes such as IGF-1, Spi2.2, fibrinogen, GADD45, and PPAR $\alpha$ (32). Quantitative real-time RT-PCR analysis of the relative concentrations of 4 genes (IGF-1, PPAR $\alpha, C Y P 8 b 1$, and PIM-3) in the 2 models studied confirmed the results obtained by microarray analysis (Figure 4, D and E). Taken together, these results clearly demonstrate that the absence of SOCS2 creates a state of hypersensitivity to $\mathrm{GH}$ actions in the liver.

All 3 domains of SOCS2 play crucial functions. Given the evidence suggesting that SOCS2 negatively regulates GH signaling, we sought to understand the mechanism and nature of the SOCS2-GH receptor interaction. SOCS proteins have been defined as consisting of a central SH2 domain, an N-terminal domain of varying length, and a C-terminal motif termed the SOCS box $(33,34)$. While each of the 3 domains for SOCS1 and SOCS3 has been ascribed a function, little is known regarding the role each domain plays in SOCS2 regulation of GH function. Studies using SOCS2 overexpression systems have found that a low level of SOCS2 partially inhibits GH signaling, while higher concentrations cause a recovery and enhancement of signaling, implicating it as a dual effector molecule $(35,36)$. This hypothesis was strengthened with the observation that mice transgenically overexpressing SOCS2 at high levels suffered a mild excessive growth phenotype (28). Transient transfection assays, in which mutated SOCS2 proteins were expressed, were used to elucidate these roles (Figure 5A). SOCS2 that had a point mutation in a conserved arginine residue within the $\mathrm{SH} 2$ domain showed only slightly impaired inhibitory or enhancement effects, whereas the mutation of 2 additional sites next to this residue led to a more complete reduction of SOCS2 activity (Figure 5B). SOCS2 lacking the $\mathrm{N}$ terminus failed to have any significant effects on $\mathrm{GH}$ mediated STAT5 reporter activity, but SOCS2 with the $\mathrm{N}$ terminus of SOCS1 substituted onto the molecule displayed some inhibitory capacity at higher concentrations of transfected construct (Figure 5C). A SOCS2 construct lacking the SOCS box displayed no inhibitory effects at all, but surprisingly triggered an enhancement of signaling even at low concentrations (Figure 5D). Other researchers have found that the SOCS-box motif from a range of SOCS molecules binds Elongin B and C complexes $(37,38)$, and we found an association between SOCS2 and Elongin B and C in immunoprecipitation studies (Figure 5E).

SOCS2 actions are dependent upon specific sites on the GH receptor. We have previously shown that SOCS2 interacts with endogenous GH receptor from a number of different mouse tissues and that this interaction occurs at Tyr595 in a phosphorylationdependent manner (28). Modification of the recombinant SOCS2 protein purification strategy to use cobalt metal ion affinity resin and thrombin to enzymatically cleave NusA from 
A
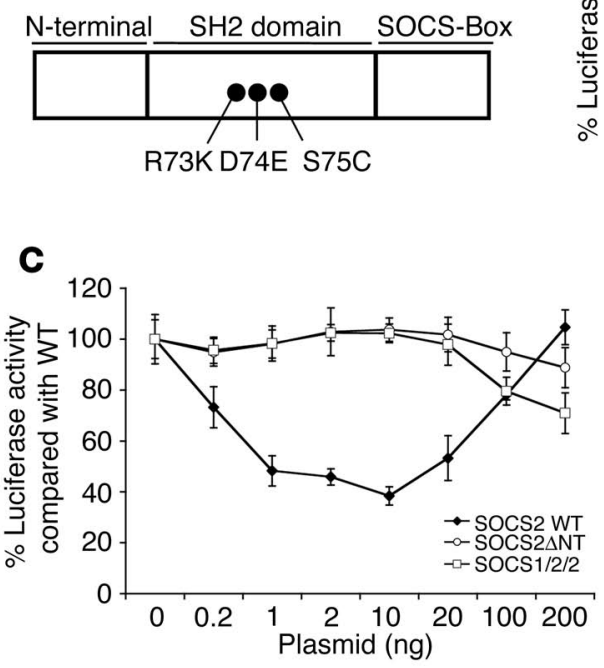

B
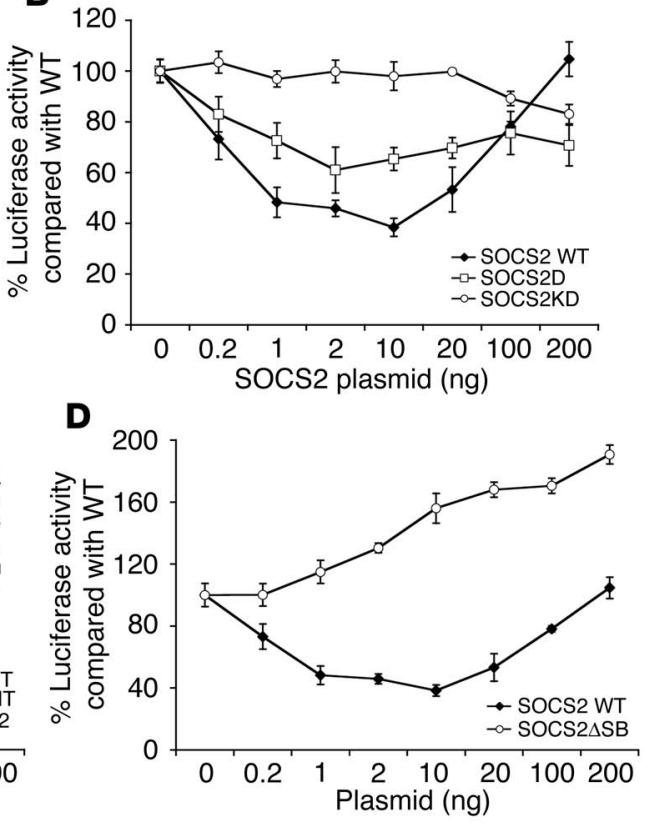

$\mathbf{E}$

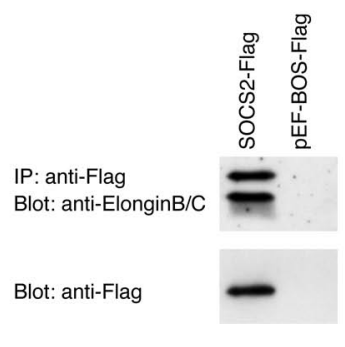

Figure 5

SOCS2 motif control of GH signaling. (A) A schematic diagram of SOCS2 is provided to help clarify mutant constructs used and residues mutated in the SH2 domain. (B-D) 293T cells were transfected with pig GH receptor and SOCS2 (SOCS2 WT), or with the following SOCS2 mutant constructs: (B) SOCS2 with a point mutation in the SH2 domain R73K (SOCS2 D) or SOCS2 with a triple mutation at R73K, D74E, and $\mathrm{S} 75 \mathrm{C}$ in the SH2 domain (SOCS2 KD); (C) SOCS2 lacking the 37-AA N terminus (SOCS2 $\triangle \mathrm{NT}$ ) or SOCS2 with the N-terminal region of SOCS1 (SOCS1/2/2); or (D) SOCS2 lacking the 39-AA C terminus (SOCS2 $\triangle$ SB) at a range of plasmid concentrations (ng). The transfected cells were then stimulated with rpGH and the luciferase activity from an LHRE-luciferase reporter was measured. Data is corrected for transfection efficiency by cotransfection of a $\beta$-galactosidase-expressing plasmid. Luciferase activity was corrected using values obtained in the absence of $\mathrm{GH}$, then expressed as a percentage of wild-type activity, which was assigned a value of $100 \%$. Experiments were performed in triplicate, and data presented here are representative of 3 independent experiments. (E) Flag-tagged SOCS2 and empty vector were transfected into 293T cells, lysed, and immunoprecipitated using antibodies against Flag. After separation on SDS-PAGE and Western transfer, blots were probed with antibodies against Elongins $B$ and $C$, then stripped and reprobed with antibodies against the Flag epitope.

SOCS2 protein led to a significant stabilization of protein activity (data not shown), thus allowing a more thorough examination of SOCS2-GH receptor interactions.

Biomolecular interaction analysis, using recombinant SOCS2 $\mathrm{SH} 2$ domain protein passed over phosphorylated peptides derived from the $\mathrm{GH}$ receptor fixed to a biosensor chip, confirmed the Tyr595 interaction and its dependence on phosphorylation, but also indicated that an additional residue, Tyr487, is also a site of interaction (Figure 6). Interestingly, Tyr595 and Tyr487 have previously been implicated as SHP2 binding sites that regulate GH receptor signaling (39). Biomolecular interaction analysis of recombinant SHP2 protein binding to GH receptor-derived peptides confirmed Tyr595 and Tyr487 interactions, but also indicated some binding with the Tyr534 residue (Figure 6). Verification of SOCS2-GH receptor peptide interactions was performed using an AlphaScreen (PerkinElmer Life Sciences) interaction assay $(40,41)$. The $\alpha$-screen assay utilizes donor beads coated with phosphorylated peptide and acceptor beads coated with recombinant SOCS2-SH2 domain protein. Interaction between phosphopeptide and SOCS2 brings the acceptor and donor beads into close proximity, and excitation of the donor beads by laser light $(680 \mathrm{~nm})$ induces production of highly reactive singlet oxygen that diffuses from the donor bead for a distance of approximately $200 \mathrm{~nm}$ in aqueous solution before rapidly decaying. When an acceptor bead is held in close proximity to the donor bead, singlet oxygen reacts with a reagent in the acceptor beads to generate chemiluminescence of 580 to $620 \mathrm{~nm}$. The intensity of the fluorescence output therefore provides a quantifiable measurement of the SOCS2/phosphopeptide binding interaction. Analysis of SOCS2/peptide interactions using the $\alpha$-screen assay showed that phosphorylated Tyr595 and Tyr487 peptides bound to the SOCS2 SH2 domain with high affinity compared to Tyr332, Tyr534, and nonphosphorylated Tyr595 (Table 1).

To validate the biological relevance of the candidate $\mathrm{GH}$ receptor interaction sites, we generated $\mathrm{GH}$ receptor constructs that lacked one or more of the tyrosine residues identified by biomolecular interaction analysis and used these in transfection studies. The activity of these constructs was examined by their ability to stimulate the STAT5-responsive luciferase reporter with and without GH stimulation (Figure 7A). Mutant receptors that lacked either Tyr487 or Tyr595 demonstrated enhanced reporter activity, and receptors lacking both showed a compounded increase in activity.

However, expression of the data in terms of fold induction after GH stimulation failed to reflect these changes (14.7-fold for wildtype receptor, 13.8-fold for Y487F receptor, 16.2-fold for Y595F receptor, and 14.6-fold for Y487,595F receptor). Real-time PCR was also used to determine that only very low levels of endogenous SOCS2 were present in $293 \mathrm{~T}$ cells when compared to exogenous SOCS2 expression levels, and this low level of endogenous SOCS2 
A
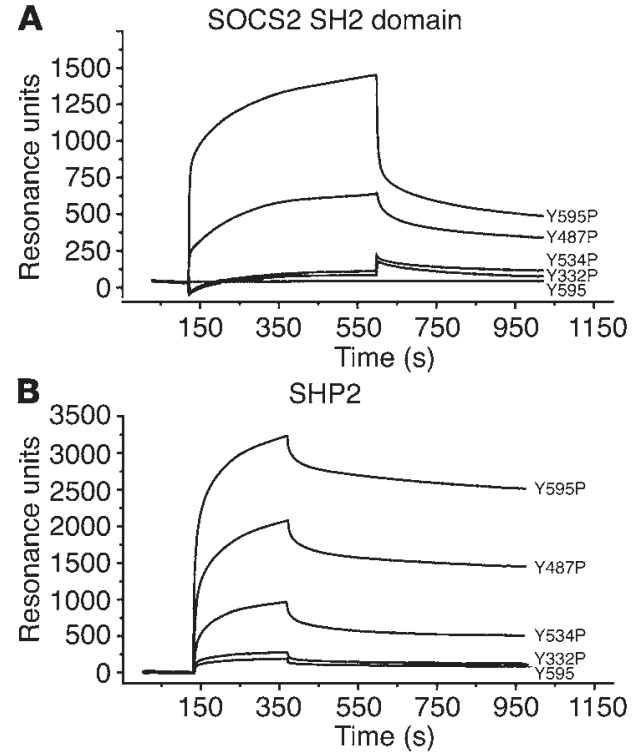

probably did not contribute to the upregulation of STAT5 activation by the Y487,595F mutant $\mathrm{GH}$ receptor in the unstimulated state (data not shown).

Titrations of SOCS2 have previously demonstrated a biphasic response in terms of GH-stimulated STAT5 reporter activity derived from wild-type GH receptors: low levels of SOCS2 inhibited approximately $50 \%$ of signaling, whereas higher levels led to a recovery or enhancement of signal (28). Consequently, it was expected that removal of SOCS2 binding sites would ameliorate these effects. Analysis of the Y487F mutant construct revealed that SOCS2 could still inhibit signaling by this receptor, although the degree of recovery may have lessened (Figure 7C). However, there appeared to be some weakening of the inhibitory effects of SOCS2 on the Y595F mutant (Figure 7B). Deletion of both the Tyr487 and Tyr595 residues removed all the inhibitory effects of SOCS2 and also significantly affected the recovery effects of SOCS2 (Figure 7D). Analysis of Tyr534 mutant SOCS2 revealed no significant role for this residue in the ability of SOCS2 to function (data not shown).

\section{Discussion}

The amelioration and reconstitution of the excessive growth phenotype in SOCS2-/- mice in response to GH provides compelling evidence that SOCS2 plays an important role in the negative regulation of GH signaling. The exact site of SOCS2 action in the somatotrophic axis has been controversial, as SOCS2 has been shown to bind to the IGF-1 receptor in yeast 2-hybrid studies (23), and the phenotype of SOCS2 knockout mice has some similarities to that of IGF-1 transgenic mice (19). However, there are no data to indicate that IGF-1 induces SOCS2 mRNA expression in vitro, and IGF-1 signaling is not perturbed in SOCS2-deficient embryonic fibroblasts (27). The hypothesis that SOCS2 is a negative regulator of GH signaling is supported by data presented here and published results showing the following: SOCS2-GH receptor interactions in vitro and in vivo (28); the role of STAT5 b in the development of the SOCS2 $2^{-/}$phenotype; modestly prolonged GH signaling in SOCS2deficient hepatocytes (27); and increases in size of non-IGF-1 responsive tissues such as the liver $(17,27)$. Furthermore, detection

\section{Figure 6}

SOCS2 interacts with tyrosine residues on the $\mathrm{GH}$ receptor. Biosensor analysis was performed on the binding between $\mathrm{GH}$ receptor-derived phosphopeptides and NusA.SOCS2 SH2 protein (A) or SHP2 protein (B). Sensorgrams correspond to binding of immobilized peptide on a streptavidin sensorchip.

of significant differences in the liver gene expression profiles in

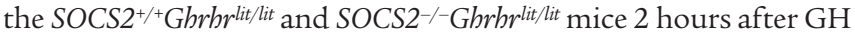
injection almost certainly precludes the role of other growth factors in mediating these differences. We do not believe that there is sufficient time for GH signaling to induce another growth factor to then act upon its own signaling system to induce SOCS2 mRNA expression, and then for the subsequent protein to exert an effect such that it could be detected in mRNA.

The hyperresponsiveness of these genes to $\mathrm{GH}$ in hepatic tissue, as well as the identification of new GH-regulated genes in the double knockout, further emphasize that SOCS2 is an important regulator of GH signaling and a therapeutic target for the enhancement of the growth-promoting effects of GH. The magnitude of organ and tissue growth in SOCS2-deficient mice in response to GH was significant, but size differences were also tissue dependent. Tissuespecific sensitivities to $\mathrm{GH}$, the level and timing of SOCS2 expression in that tissue, gender, and sexual dimorphisms all appeared to be modifying factors in controlling target sensitivity to GH. This is emphasized in the pregnancy-driven enhancement of body size in SOCS2 ${ }^{-/}$Ghrbrlit/lit females. Although the mechanism behind this phenomenon is not completely clear, it is plausible that pregnant female mice are exposed to placentally derived GH or prolactin, to which SOCS2 ${ }^{-/-} \mathrm{Ghrbl}^{\text {lit/lit }}$ mice are hyperresponsive.

The unique nature of SOCS2 action is further emphasized in the microarray studies. SOCS2-/-Ghrbrit/lit mice clearly have an enhanced GH-induced liver gene expression response compared

\section{Table 1}

$\alpha$-screen analysis of SOCS2 SH2 domain protein interactions with receptor-derived phosphopeptides

\begin{tabular}{lcccc}
\hline & \multicolumn{5}{c}{ B-PY595 } \\
Peptide (nM) & 100 & 50 & 25 & 12.5 \\
Signal/noise & 27.52 & 23.22 & 28.73 & 16.09 \\
& \multicolumn{5}{c}{ B-nonP595 } \\
Peptide (nM) & 100 & 50 & 25 & 12.5 \\
Signal/noise & 0.74 & 0.67 & 0.65 & 0.64 \\
& \multicolumn{4}{c}{ B-Y534 } \\
Peptide (nM) & 100 & 50 & 25 & 12.5 \\
Signal/noise & 0.66 & 0.77 & 0.68 & 0.78 \\
& \multicolumn{5}{c}{ B-Y487 } \\
Peptide (nM) & 100 & 50 & 25 & 12.5 \\
Signal/noise & 23.17 & 28.29 & 17.18 & 4.22 \\
& \multicolumn{5}{c}{ B-Y332 } \\
Peptide (nM) & 100 & 50 & 25 & 12.5 \\
Signal/noise & 0.75 & 0.74 & 0.83 & 0.58 \\
\hline
\end{tabular}

Peptide indicates concentration used for coating the $\alpha$-screen beads. Signal/noise indicates the ratio of the signal intensity measured at the indicated concentration of biotinylated peptide to the signal intensity measured for donor and acceptor beads without peptide. 

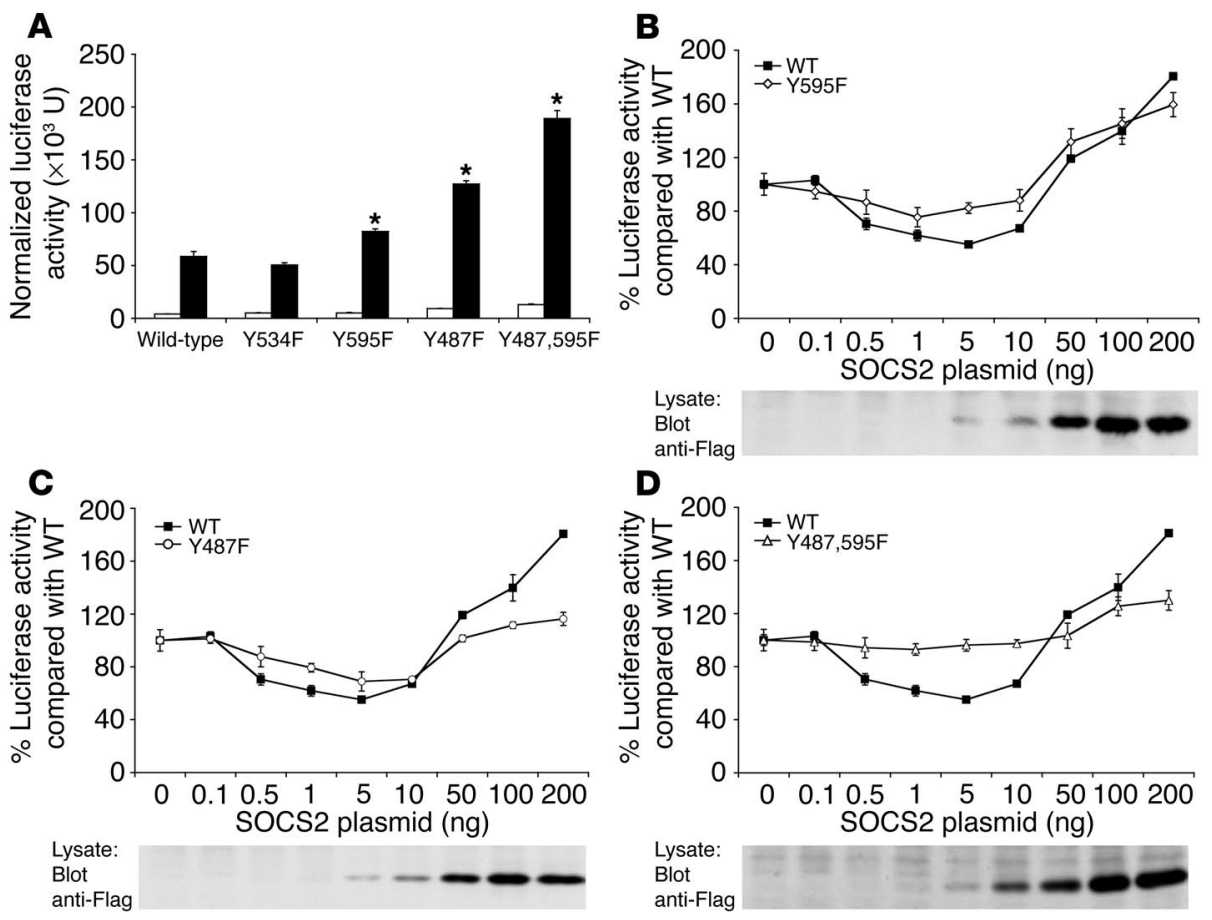

Figure 7

SOCS2 effects are mediated through Tyr487 and Tyr595. (A) 293T cells were transfected with wildtype or mutated GH receptor constructs, then they were starved of (white bars) or stimulated with rpGH (black bars), and the luciferase activity from an LHRE-luciferase reporter was measured. Data were corrected for transfection efficiency by cotransfection of a $\beta$-galactosidase-expressing plasmid. ${ }^{*} P<0.05$, significant difference between stimulated receptors. (B-D) 293T cells were transfected with wild-type GH receptor, (B) Y595F GH receptor, (C) Y487F GH receptor, or (D) Y487,595F GH receptor and increasing concentrations of SOCS2 plasmid (ng). Data were corrected for transfection efficiency by cotransfection of a $\beta$-galactosidase-expressing plasmid. Luciferase activity was corrected using values obtained in the absence of $\mathrm{GH}$, then expressed as a percentage of wild-type $\mathrm{GH}$ receptor activity without SOCS2 expression, which was assigned a value of $100 \%$. Experiments were performed in triplicate and data presented here are representative of 3 independent experiments. Expression of SOCS2 was confirmed by Western blotting of cell lysate with antibodies against the Flag epitope at the $\mathrm{N}$ terminus of the SOCS2 expression construct.

to SOCS2 ${ }^{+/+}$Ghrbrlit/lit mice, although the magnitude and type of response do not simply fit a model of a completely deregulated $\mathrm{GH}$ receptor signaling action. IGF-1 is a classic GH-induced gene of the liver, and it has been shown to be a contributor to somatic growth (42). The overexpression of IGF-1 in SOCS2-/-Ghrbrit/lit mice may contribute to their increased growth response when administered GH. The appearance of other GH-regulated genes such as PPAR $\alpha$ and Spi2.2 fits the proposed model, but the alterations of other genes that were previously thought to be unresponsive to GH (e.g., PIM-3 and CYP8b1) indicate that SOCS2 function is more complicated than first thought. Similar observations have been made in other SOCS knockout models where IL-6 stimulation of SOCS3-deficient livers led to exaggerated gene expression of IL-6-responsive genes, as compared to wild-type expression, but it also let to the induction of other genes thought to be classically IFN- $\gamma$-inducible genes $(12,14)$. The magnitude of change in $\mathrm{GH}$-induced expression with a lack of SOCS2 was not as large as might be predicted from that observed in SOCS3-deficient livers stimulated with IL-6 (14), but these small changes in signaling and expression may be large when considering that they would be cumulative over an animal's somatic growth period.
Our results demonstrate that all 3 domains of SOCS2 may play a role in protein function. The $\mathrm{SH} 2$ domain of a number of SOCS proteins plays a central role in their function and SOCS2 is no different. Whereas mutating the conserved arginine in the SOCS1 SH2 domain was sufficient to eliminate the inhibitory activity of SOCS1 (43), SOCS2 required additional mutations to become inactive. The reasons for this are unclear, but it may reflect redundancy in SOCS2 generated by its ability to bind a number of different residues on the GH receptor. The SOCS box of SOCS2 plays a central role in the negative regulation of $\mathrm{GH}$ signaling. This is intriguing, as removal of the SOCS box from other SOCS molecules does not impede inhibitory function in overexpression studies, although the SOCS box of SOCS1 has been shown to play an important role physiologically (44). Consequently, this may reflect a difference in the mechanism of SOCS2 action, with a strong reliance on ubiquitination and degradation to terminate $\mathrm{GH}$ signaling, rather than on inhibition of receptor function. Consistent with this interpretation, SOCS1 and SOCS3 contain a kinase inhibitory region that is absent in SOCS2 (45).

We have shown here that it is necessary to delete both the Y487 and Y595 residues to remove the inhibitory effects of SOCS2 on GH signaling. Mutations of these 2 sites have previously been shown to result in the prolongation of the GH-activated JAK/STAT5 pathway. SHP2 binds these residues and is thought to act as the negative regulator of the receptor (39). However, when the function of SHP2 is directly tested in overexpression systems, it acts as a positive regulator of $\mathrm{GH}$ signaling (46). In retrospect, the data supporting a role for SHP2 as a negative regulator generated using GH receptor tyrosine mutations could now be reinterpreted as SOCS2 mediating the inhibition directly or acting to inhibit SHP2 action (39). This model has a number of similarities to that for SOCS3 and SHP2 binding to the gp130 receptor (47-49). The observations of significant increases in luciferase output of the GH mutant receptors when stimulated with hormone, as well as increased basal levels without stimulation, are also seen in similar studies in which the SOCS3 binding site of gp130 was mutated (48). A possible explanation for this phenomenon is that basal receptor activity also utilizes low levels of SOCS2 for negative control, and mutation of SOCS2 binding residues causes a proportional increase in luciferase output compared to the stimulated levels. Presuming that SOCS2 protein levels are low in unstimulated cells, it is possible that other negative regulators can interact with the receptor through these tyrosines. Another candidate is PTP1B, a tyrosine 
phosphatase known to interact with the GH receptor and has been confirmed to have negative actions on $\mathrm{GH}$ signaling (50). A negative action of SHP2 on certain tissues cannot be excluded, and the fact that SOCS2 and SHP2 both bind the same sites on the $\mathrm{GH}$ receptor sets the scene for potential interplay between these molecules. It is anticipated that further characterization of these phosphatases and SOCS2 interactions in the negative regulation of the GH receptor will decipher the nature of interplay that may exist between these molecules and provide further insights into the exact mechanism by which SOCS2 inhibits GH signaling.

Converting the information gathered in this manuscript into a clinical application is the next step. The $\alpha$-screen assay technology used in this work forms the basis of a high-throughput screen, and we are currently using this approach to screen chemical compound libraries for small-molecule inhibitors of SOCS2-GH receptor interactions. An alternate approach would be to downregulate SOCS2 mRNA expression by using antisense or siRNA approaches, which are becoming more prevalent in strategies to target intracellular molecules. It is hoped that such approaches may be useful in the development of new strategies targeting growth disorders by replacing or amplifying the effects of exogenous $\mathrm{GH}$ administration.

\section{Methods}

Animals. Ghrbrlitlit mice were obtained from Jackson ImmunoResearch Laboratories and were maintained by mating Gbrbr ${ }^{\text {lit } / \text { lit }}$ or Ghrbr ${ }^{W T / l i t}$ females with $G h r b r^{l i t / l i t}$ males. Mice were phenotyped for the little mutation after weaning. SOCS2 ${ }^{-/-}$mice were mated with Ghrbrit/lit mice and genotyped for SOCS2 as previously described (17), while genotyping of the little mutation was performed by PCR across the mutation and direct sequencing of PCR products (51). SOCS2 $2_{-}^{-}$Ghrbrlit/lit mice were generated from matings between male SOCS2 $2^{---}$Ghrbr $^{\text {lit/lit }}$ or SOCS2 $2^{-/-}$Ghrhr $^{\text {lit } / W T}$ mice and female SOCS2 $2^{-/-}$Ghrbr $^{\text {lit } / l i t}$ or SOCS2 $2_{--G h r b r}^{l i t / W T}$ mice. All experiments were performed in accordance with National Health and Medical Research Council of Australia guidelines and were approved by the Melbourne Health Research Directorate Animal Ethics Committee (Melbourne, Victoria, Australia).

For GH-induced growth experiments, $10 \mu \mathrm{g}$ of recombinant pig GH (rpGH) dissolved in $50 \mu \mathrm{l}$ saline, or $50 \mu \mathrm{l}$ saline alone, was injected subcutaneously twice daily on weekdays and once daily on weekends. The site of injection was rotated daily to minimize discomfort, and weight measurements were taken in the morning before injection.

Microarray experiments were performed on livers from male SOCS2+/+ Ghrbrlit/lit and SOCS2--Ghrbrlit/lit mice that had been injected with $100 \mu \mathrm{g}$ rpGH 2 hours before sacrifice.

Histological examination. Skin sections were prepared from tissues fixed in $10 \%$ saline-buffered formalin by standard techniques, stained with hematoxylin and eosin, and examined by light microscopy. Bone lengths were measured using $\mathrm{x}$-ray imaging as previously described (17). Other bone measurements were obtained by computerized tomography using a Stratec pQCT XCT Research M (Norland; v5.4B) operating at a resolution of $70 \mu \mathrm{m}$ as previously described (52). Trabecular bone mineral density was determined ex vivo, with a metaphyseal PQCT scan of the distal femur and the proximal tibia. The scan was positioned in the metaphysis at a distance corresponding to $4 \%$ of the total length of either the femur or the tibia. The trabecular bone region was defined as the inner $45 \%$ of the total crosssectional area. Cortical bone parameters were determined ex vivo with a mid-diaphyseal PQCT scan of the femur and tibia.

Elongin $B$ and $C$ interaction. Either pEF-Flag or pEF-SOCS2-Flag plasmids (200 ng) (43) was transfected into $293 \mathrm{~T}$ human embryonic kidney cells. Cells were washed and lysed 48 hours after transfection, and lysates were precipitated with antibodies against the Flag epitope (monoclonals 9H1 and 9B4 provided by David Huang, WEHI). After SDS-PAGE separation and Western transfer, blots were probed with antibodies against Elongin B and C (provided by Zhang-Guo Jiang, WEHI) then reprobed with antibodies directed against the Flag epitope.

Vector construction. Mutations in the SH2 domain of SOCS2 were generated using splice overlap extension PCR of the SOCS2R73K plasmid (43) to generate additional mutations, D74E and S75C. SOCS2 $\Delta$ box (lacking the last 39 amino acids) and SOCS2 $\Delta$ Nterm (lacking the first 37 amino acids) constructs were generated by PCR to give fragments with in-frame $A s c \mathrm{I}$ and $M l u \mathrm{I}$ restriction enzyme sites at the $\mathrm{N}$ and $\mathrm{C}$ termini, respectively, and subcloned into pEF-Flag-I to give proteins with an N-terminal Flag epitope tag. A plasmid encoding the $\mathrm{N}$ terminus of SOCS1 (amino acids 1-78) fused to the SOCS $2 \Delta$ Nterm was generated using PCR-based techniques as previously described (43). GH receptor constructs for mutational analysis were generated by excising the $\mathrm{GH}$ receptor coding region from the pMet-Ig7 GHR plasmid (sourced from Nils Billestrup, Steno Diabetes Center, Gentofte, Denmark [53]) and inserting it into the pEF-BOS vector. The Y487F, Y595F, Y534F, and Y487,595F mutants were generated by using overlapping PCR strategies to introduce mutations at these sites. All constructs were sequenced in their entirety before use.

Luciferase assays. $293 \mathrm{~T}$ cells were transfected with Lipofectamine 2000 (Invitrogen Corp.) reagents according to the manufacturer's instructions. For SOCS2 domain analysis, $4 \times 10^{5}$ cells were transfected with $200 \mathrm{ng}$ each of $\mathrm{pIG}-\mathrm{GH}$ receptor plasmid, lactogenic hormone response element-luc (LHRE-luc) reporter plasmid, $\beta$-galactosidase plasmid, and 0-200 ng pEF-SOCS2-Flag plasmid (43) made up to $200 \mathrm{ng}$ with pEF-BOS plasmid into a 24 -well plate 6 hours after cells were plated. Twenty-four hours later, cells were washed once with mouse-tonicity PBS (18.9 $\mathrm{mM} \mathrm{Na}_{2} \mathrm{HPO}_{4}, 3.9 \mathrm{mM} \mathrm{NaH} \mathrm{PO}_{4} \times \mathrm{H}_{2} \mathrm{O}$, and $148 \mathrm{mM} \mathrm{NaCl}$ ) and the culture medium was replaced with DMEM containing 1\% BSA. Cells were left to equilibrate for 1 hour before $500 \mathrm{ng} / \mathrm{ml}$ of $\mathrm{rpGH}$ was added to appropriate groups. Cells were incubated for a further 16 hours before being lysed and assayed for luciferase and $\beta$-galactosidase activity as described (28). Luciferase activity was normalized to $\beta$-galactosidase activity. Luciferase assays examining point mutations in $\mathrm{GH}$ receptors were performed as described above except that only 2 ng of each pEF-GH receptor plasmid was used.

Recombinant protein expression. Murine SOCS2 SH2 domain was produced as described previously (28), with the following modifications. Bacterial lysate containing NusA-hexaHis-SOCS2-SH2 fusion protein was passed through a Talon column (cobalt metal ion affinity chromatography [BD Biosciences - Clontech]) to bind fusion protein before the NusA protein was cleaved from the column at a thrombin cleavage site using thrombin (SigmaAldrich). The column was washed extensively with PBS ( $\mathrm{pH}$ 6.4) before the SOCS2 SH2 domain was eluted with $150 \mathrm{mM}$ imidazole in PBS (pH 7.5). Fractions were collected and separated by SDS-PAGE to determine purity. Recombinant SHP2 protein was produced as described previously (48).

SDS-PAGE analysis and Western blotting. All SDS-PAGE, Western blotting, and detection of Flag-tagged proteins was performed as described previously $(27,28)$.

Biomolecular interaction analysis. All analyses were performed essentially as previously described for SOCS3 (48). Briefly, biotinylated phosphopeptides $(1 \mu \mathrm{g} / \mathrm{ml})$ were bound to streptavidin-coated biosensor chips (SA5, Biacore) at a density of 400 RU. SOCS2 binding studies were measured in buffer A (20 mM HEPES, $150 \mathrm{mM}$ sodium chloride, $3.4 \mathrm{mM}$ EDTA, and 0.005\% (v/v) Tween 20) with a flow rate of $10 \mu \mathrm{l} / \mathrm{min}$. Chips were washed with $6 \mathrm{M}$ guanidinium hydrochloride between binding measurements to remove residual SOCS2 protein, then washed with buffer A. Binding profiles were analyzed using BIAEVALUATION software Ver. 3.0 (Pharmacia). 
AlphaScreen binding assay. Nickel chelate-derived AlphaScreen beads (PerkinElmer Life Sciences) were diluted to a final concentration of $5 \mathrm{mg} / \mathrm{ml}$ in buffer (bead buffer) containing $0.1 \mathrm{mg} / \mathrm{ml}$ casein, $50 \mathrm{mM} \mathrm{HEPES} \mathrm{(pH} \mathrm{7.4),}$ $10 \mathrm{mM}$ dithithreitol, $100 \mathrm{mM} \mathrm{NaCl}$, and $0.1 \%$ Tween 20 . Hexa-His-tagged SOCS2-SH2 domain was added at a final concentration of $16 \mathrm{nM}$ and the mixture was incubated for 30 minutes at room temperature. The biotinylated phosphopeptide was mixed at a concentration of $32 \mathrm{nM}$ with $5 \mathrm{mg} / \mathrm{ml}$ of streptavidin-coated $\alpha$-screen beads in bead buffer and incubated at room temperature for 30 minutes. The assay was performed by mixing $10 \mathrm{ml}$ of each bead stock solution in the wells of a 384-well microtiter plate and incubating the mixture at room temperature for 2.5 hours. The assay results were read using a Fusion Alpha plate reader (PerkinElmer Life Sciences). For peptide competition experiments, the non-biotinylated competitor peptide was diluted in bead buffer and $5 \mathrm{ml}$ of this stock solution was mixed with $10 \mathrm{ml}$ of the SOCS2 bead solution in the wells of the microtiter plate. The mixture was incubated for 30 minutes at room temperature before $10 \mathrm{ml}$ of streptavidin beads coated with $32 \mathrm{nM}$ of Tyr 595 was added. The rest of the assay was performed as described above.

Microarray analysis. A microarray containing 16,500 mouse oligo 70-mers, printed twice and produced at the SweGene DNA Microarray Resource Center at Lund University, was used to evaluate the hepatic GH responsiveness in the 2 models studied. Total RNA was isolated by homogenization of liver tissue using TRIzol Reagent (Invitrogen Corp.), according to the protocol supplied by the manufacturer. Twelve independent hybridizations were performed, comparing individual animals from the different experimental groups (SOCS2 ${ }^{+/+} \mathrm{Ghrhr}^{\text {lit } / \text { lit }}$ vs. SOCS2 $2^{-/-} \mathrm{Ghrbr}{ }^{\text {lit } / \text { lit }}$,

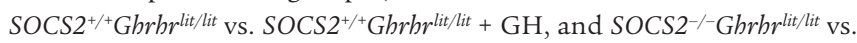
SOCS2 $\left.2^{-/-G h r b r l i t / l i t}+\mathrm{GH}\right)$. The protocols employed for probe labeling, purification, and hybridization were essentially as described previously (32). Total RNA $(20 \mu \mathrm{g})$ was used in each of the labeling reactions and balance dye swaps were included in the experimental design. Image analysis was performed using GenePix Pro software (Axon Instruments). Fluorescence ratios were normalized (54) using the locally weighted scatter plot smoother (LOWESS) method in the statistics for microarray (SMA) package (Axon Instruments). Individual measurements for specific probes were calculated as the gene average of 2 probe measurements. The variability of the analysis was estimated using significance analysis of microarray (SAM) software (Stanford University) (55). A q value was assigned for each of the detectable genes in the array. This value is similar to the $P$ values, measuring the lowest false discovery rate (FDR) at which the differential expression (the ratio between control and treatment) of the gene is called significant. In this study, genes with a FDR value of less than $5 \%$ were listed as differentially expressed. In order to allow for comparison between models, the analysis was performed on gene probes that were consistently detected in both models (i.e., in 3 out of the 4 independent measurements). A total of 2,219 gene-specific probes were used for the comparison. Statistical analysis comparing the average of log ratio values in both models was performed using Student's $t$ test analysis; complete results are available at http://www.cmm.ki.se/gnorstedt/ CCMCore/Index.html.

Gene expression analysis by real-time quantitative RT-PCR. The expression of IGF-1, PPAR- $\alpha$, CYP8b1 (12 $\alpha$ hydroxylase), and the serine/threonine kinase PIM-3 was analyzed using quantitative real-time PCR (DNA Engine Opticon 2 System; MJ Research Inc.) in RNA samples from individual animals. Briefly, $2 \mu \mathrm{g}$ of total RNA treated with DNase I (Promega) was reverse-transcribed using a First Strand cDNA Synthesis Kit (Invitrogen Corp.). Gene-specific primers corresponding to the target genes were used to generate the amplicons.

To measure the relative concentration of the gene expression, $2 \mu \mathrm{l}$ of each sample (dilution 1:3) was analyzed in duplicate. Real-time PCR was performed in a $20 \mu \mathrm{l}$ volume with $2 \mu \mathrm{l}$ of respective cDNA and $0.4 \mu \mathrm{M}$ primers. Nucleotides, Taq polymerase, reaction buffer, and SYBR Green I dye were supplied in the iQ SYGR Green Supermix (Bio-Rad Laboratories Inc.). The amplification program consisted of 1 cycle of $95^{\circ} \mathrm{C}$ for 3 minutes, followed by 45 cycles of $95^{\circ} \mathrm{C}$ for 15 seconds, 10 seconds at annealing temperature, and $72^{\circ} \mathrm{C}$ for 30 seconds; fluorescent intensity was measured at a specific acquisition temperature for each gene. The individual mRNA levels were obtained by comparison to a standard curve. $\mathrm{GH}$-induced changes in expression were calculated after normalization with the level of $\beta$-actin in each sample.

\section{Acknowledgments}

We thank Sally Cane and Janelle Lochlan for genotyping, Steven Mihajlovic for histology, Megan James for excellent animal husbandry, and Zdenka Bolcevic for comments on the manuscript. This work is supported by the Australian National Health and Medical Research Council (program grant 257500), the Australian Federal Government Cooperative Research Centres Program, the NIH (grant CA22556), Amrad Corporation Ltd., the Swedish Research Council (grant 529-2002-6766), the Wallenberg Foundation, and the Swedish Society for Medical Research. C.J. Greenhalgh is the recipient of an Australian Postdoctoral Research Fellowship.

Received for publication July 14, 2004, and accepted in revised form December 1, 2004.

Address correspondence to: Christopher J. Greenhalgh, The Walter and Eliza Hall Institute of Medical Research, 1G Royal Parade, Parkville, Victoria 3050, Australia. Phone: 61-39208-4021; Fax: 61-39208-4100; E-mail: greenhalgh@wehi.edu.au.
1. Press, M. 1988. Growth hormone and metabolism. Diabetes Metab. Rev. 4:391-414.

2. Sonksen, P.H., Salomon, F., and Cuneo, R. 1991. Metabolic effects of hypopituitarism and acromegaly. Horm. Res. 36:S27-S31.

3. [Anonymous]. 1998. Consensus guidelines for the diagnosis and treatment of adults with growth hormone deficiency: summary statement of the growth hormone research society workshop on adult growth hormone deficiency.J. Clin. Endocrinol. Metab. 83:379-381.

4. Monson, J.P. 2003. Long-term experience with GH replacement therapy: efficacy and safety. Eur. J. Endocrinol. 148:S9-S14.

5. Bramnert, M., et al. 2003. Growth hormone replacement therapy induces resistance by activating the glucose-fatty acid cycle. J. Clin. Endocrinol. Metab. 88:1455-1463.
6. Hanada, T., Kinjyo, I., Inagaki-Ohara, K., and Yoshimura, A. 2003. Negative regulation of cytokine signaling by CIS/SOCS family proteins and their roles in inflammatory diseases. Rev. Physiol. Biochem. Pharmacol. 149:72-86.

7. Alexander, W.S. 2002. Suppressors of cytokine signalling (SOCS) in the immune system. Nat. Rev. Immunol. 2:410-416.

8. Alexander, W.S., et al. 1999. SOCS1 is a critical inhibitor of interferon gamma signaling and prevents the potentially fatal neonatal actions of this cytokine. Cell. 98:597-608.

9. Lindeman, G.J., et al. 2001. SOCS1 deficiency results in accelerated mammary gland development and rescues lactation in prolactin receptordeficient mice. Genes Dev. 15:1631-1636.

10. Chong, M.M., et al. 2003. Suppressor of cytokine signaling-1 is a critical regulator of interleukin-7- dependent CD8+ T cell differentiation. Immunity. 18:475-487.

11. Roberts, A.W., et al. 2001. Placental defects and embryonic lethality in mice lacking suppressor of cytokine signaling 3. Proc. Natl. Acad. Sci. U. S. A. 98:9324-9329.

12. Lang, R., et al. 2003. SOCS3 regulates the plasticity of gp130 signaling. Nat. Immunol. 4:546-550.

13. Takahashi, Y., et al. 2003. SOCS3: an essential regulator of LIF receptor signaling in trophoblast giant cell differentiation. EMBO J. 22:372-384.

14. Croker, B.A., et al. 2003. SOCS3 negatively regulates IL-6 signaling in vivo. Nat. Immunol. 4:540-545.

15. Yasukawa, H., et al. 2003. IL-6 induces an antiinflammatory response in the absence of SOCS3 in macrophages. Nat. Immunol. 4:551-556.

16. Croker, B.A., et al. 2004. SOCS3 is a critical physiological negative regulator of G-CSF signaling and 
emergency granulopoiesis. Immunity. 20:153-165.

17. Metcalf, D., et al. 2000. Gigantism in mice lacking suppressor of cytokine signalling-2. Nature. 405:1069-1073.

18. Palmiter, R.D., et al. 1982. Dramatic growth of mice that develop from eggs microinjected with metallothionein-growth hormone fusion genes. Nature. 300:611-615.

19. Mathews, L.S., et al. 1988. Growth enhancement of transgenic mice expressing human insulin-like growth factor I. Endocrinology. 123:2827-2833.

20. Horvat, S., and Medrano, J.F. 2001. Lack of Socs2 expression causes the high-growth phenotype in mice. Genomics. 72:209-212.

21. Hansen, J.A., Lindberg, K., Hilton, D.J., Nielsen, J.H., and Billestrup, N. 1999. Mechanism of inhibition of growth hormone receptor signaling by suppressor of cytokine signaling proteins. $\mathrm{Mol}$. Endocrinol. 13:1832-1843.

22. Ram, P.A., and Waxman, D.J. 1999. SOCS/CIS protein inhibition of growth hormone-stimulated STAT5 signaling by multiple mechanisms. J. Biol. Chem. 274:35553-35561.

23. Dey, B.R., Spence, S.L., Nissley, P., and Furlanetto, R.W. 1998. Interaction of human suppressor of cytokine signaling (SOCS)-2 with the insulin-like growth factor-I receptor. J. Biol. Chem. 273:24095-24101.

24. Lopaczynski, W. 1999. Differential regulation of signaling pathways for insulin and insulin-like growth factor I. Acta Biochim. Pol. 46:51-60.

25. Udy, G.B., et al. 1997. Requirement of STAT5b for sexual dimorphism of body growth rates and liver gene expression. Proc. Natl. Acad. Sci. U. S. A 94:7239-7244.

26. Teglund, S., et al. 1998 . Stat $5 \mathrm{a}$ and Stat $5 \mathrm{~b}$ proteins have essential and nonessential, or redundant, roles in cytokine responses. Cell. 93:841-850.

27. Greenhalgh, C.J., et al. 2002. Growth enhancement in suppressor of cytokine signaling 2 (SOCS-2)deficient mice is dependent on signal transducer and activator of transcription 5b (STAT5b). Mol. Endocrinol. 16:1394-1406.

28. Greenhalgh, C.J., et al. 2002. Biological evidence that SOCS- 2 can act either as an enhancer or suppressor of growth hormone signaling. J. Biol. Chem. 277:40181-40184.

29. Wajnrajch, M.P., Gertner, J.M., Harbison, M.D., Chua, S.C., Jr., and Leibel, R.L. 1996. Nonsense mutation in the human growth hormone-releasing hormone receptor causes growth failure analogous to the little (lit) mouse. Nat. Genet. 12:88-90.

30. Beamer, W.H., and Eicher, E.M. 1976. Stimulation of growth in the little mouse. J. Endocrinol. 71:37-45.

31. Flores-Morales, A., et al. 2001. Endoplasmic reticulum stress prolongs $\mathrm{GH}$-induced Janus kinase (JAK2)/signal transducer and activator of transcription (STAT5) signaling pathway. Mol. Endocrinol. 15:1471-1483.

32. Tollet-Egnell, P., et al. 2001. Gene expression profile of the aging process in rat liver: normalizing effects of growth hormone replacement. Mol. Endocrinol. 15:308-318.

33. Hilton, D.J., et al. 1998. Twenty proteins containing a C-terminal SOCS box form five structural classes. Proc. Natl. Acad. Sci. U. S. A. 95:114-119.

34. Kile, B.T., et al. 2002. The SOCS box: a tale of destruction and degradation. Trends Biochem. Sci. 27:235-241.

35. Favre, H., Benhamou, A., Finidori, J., Kelly, P.A., and Edery, M. 1999. Dual effects of suppressor of cytokine signaling (SOCS-2) on growth hormone signal transduction. FEBS Lett. 453:63-66.

36. Adams, T.E., et al. 1998. Growth hormone preferentially induces the rapid, transient expression of SOCS-3, a novel inhibitor of cytokine receptor signaling. J. Biol. Chem. 273:1285-1287.

37. Kamura, T., et al. 1998. The Elongin BC complex interacts with the conserved SOCS-box motif present in members of the SOCS, ras, WD-40 repeat, and ankyrin repeat families. Genes Dev. 12:3872-3881.

38. Zhang, J.G., et al. 1999. The conserved SOCS box motif in suppressors of cytokine signaling binds to elongins $\mathrm{B}$ and $\mathrm{C}$ and may couple bound proteins to proteasomal degradation. Proc. Natl. Acad. Sci.U.S. A. 96:2071-2076.

39. Stofega, M.R., Herrington, J., Billestrup, N., and Carter-Su, C. 2000. Mutation of the SHP-2 binding site in growth hormone $(\mathrm{GH})$ receptor prolongs GH-promoted tyrosyl phosphorylation of GH receptor, JAK2, and STAT5B. Mol. Endocrinol. 14:1338-1350.

40. Ullman, E.F., et al. 1994. Luminescent oxygen channeling immunoassay: measurement of particle binding kinetics by chemiluminescence. Proc. Natl. Acad. Sci. U. S. A. 91:5426-5430.

41. Ullman, E.F., et al. 1996. Luminescent oxygen channeling assay (LOCI): sensitive, broadly applicable homogeneous immunoassay method. Clin. Chem. 42:1518-1526.

42. Yakar, S., et al. 2002. Circulating levels of IGF-1 directly regulate bone growth and density. J. Clin. Invest. 110:771-781. doi:10.1172/JCI200215463.

43. Nicholson, S.E., et al. 1999. Mutational analyses of the SOCS proteins suggest a dual domain require- ment but distinct mechanisms for inhibition of LIF and IL-6 signal transduction. EMBO J. 18:375-385.

44. Zhang, J.G., et al. 2001. The SOCS box of suppressor of cytokine signaling- 1 is important for inhibition of cytokine action in vivo. Proc. Natl. Acad. Sci. U. S. A. 98:13261-13265.

45. Yasukawa, H., et al. 1999. The JAK-binding protein JAB inhibits Janus tyrosine kinase activity through binding in the activation loop. EMBOJ. 18:1309-1320.

46. Kim, S.O., Jiang, J., Yi, W., Feng, G.S., and Frank, S.J. 1998. Involvement of the Src homology 2-containing tyrosine phosphatase SHP-2 in growth hormone signaling. J. Biol. Chem. 273:2344-2354.

47. Schmitz, J., Weissenbach, M., Haan, S., Heinrich, P.C., and Schaper, F. 2000. SOCS3 exerts its inhibitory function on interleukin- 6 signal transduction through the SHP2 recruitment site of gp130. J. Biol. Chem. 275:12848-12856.

48. Nicholson, S.E., et al. 2000. Suppressor of cytokine signaling-3 preferentially binds to the SHP-2-binding site on the shared cytokine receptor subunit gp130. Proc. Natl. Acad. Sci. U. S. A. 97:6493-6498.

49. Fairlie, W.D., De Souza, D., Nicola, N.A., and Baca, M. 2003. Negative regulation of gp130 signalling mediated through tyrosine-757 is not dependent on the recruitment of SHP2. Biochem. J. 372:495-502.

50. Gu, F., et al. 2003. Protein tyrosine phosphatase 1B attenuates growth hormone-mediated JAK2-STAT signaling. Mol. Cell Biol. 23:3753-3762.

51. Godfrey, P., et al. 1993. GHRH receptor of little mice contains a missense mutation in the extracellular domain that disrupts receptor function. Nat. Genet. 4:227-232.

52. Windahl, S.H., Vidal, O., Andersson, G., Gustafsson, J.A., and Ohlsson, C. 1999. Increased cortical bone mineral content but unchanged trabecular bone mineral density in female $E R \beta^{-/-}$mice. J. Clin. Invest. 104:895-901.

53. Hansen, L.H., et al. 1996. Identification of tyrosine residues in the intracellular domain of the growth hormone receptor required for transcriptional signaling and Stat5 activation. J. Biol. Chem. 271:12669-12673.

54. Pang, S.T., et al. 2002. Gene expression profiling of androgen deficiency predicts a pathway of prostate apoptosis that involves genes related to oxidative stress. Endocrinology. 143:4897-4906.

55. Tusher, V.G., Tibshirani, R., and Chu, G. 2001. Significance analysis of microarrays applied to the ionizing radiation response. Proc. Natl. Acad. Sci. U. S. A. 98:5116-5121. 